\title{
Just-in-Time Delivery Requires Just-in-Time Production X2 - Sychronising Factory and Site for Successful Prefabrication
}

\author{
Alan Mossman ${ }^{1 *}$ \\ ${ }^{1}$ Managing Director, The Change Business Ltd, Stroud, UK \\ "Corresponding author's e-mail: alanmossman@mac.com
}

\begin{abstract}
Failure to synchronize production on-site with production in the factory leads to losses for the client/owner, the Construction Manager/General Contractor (CM/GC) and subcontractors as well as to delays in the construction schedule. How can off-site fabrication of sub-assemblies be synchronised with predictable production and assembly on-site so as to increase the chances that the site is ready to receive each sub-assembly when it arrives and that site operations are not delayed by waiting for delivery of sub-assemblies? From the construction literature and the authors' personal experiences it is clear that Critical Path Methods are not fit for this purpose; rigorous, collaborative, short-term planning is much more effective. Value for practitioners: ideas for what to pay attention to, in order to reduce both work waiting for workers (or robots) and workers (or robots) waiting for work. Value for scholars: ideas for further research.
\end{abstract}

\section{KEYWORDS}

Predictable production; Just-in-time production; On-time delivery; Last Planner System.

\section{INTRODUCTION}

The benefits of off-site fabrication have been well rehearsed elsewhere. Off-site fabrication and pre-fabrication make economic sense when production/assembly on-site is predictable \& flowing. When site production, or when deliveries of sub-assemblies are unpredictable, workers at site are kept waiting and flow is impeded. Traditional project management assumes that variability in work flow is outside management control (Ballard \& Howell 2003) yet delays and waiting create no value for the client, and no-one wants to see workers standing idle. The temptation is to either put them to work doing something out of sequence or to assign them to a different project. Work done out of sequence can make subsequent tasks more difficult and it is often difficult to get workers back to site once they have been reassigned. In those circumstances traditional hand building is a much better strategy for keeping trades busy.

In their call for papers for the 2005 IGLC Prefabrication \& Assembly Championship, Ballard \& Matthews described the lean ideal as "to "simplify site installation to final assembly and commissioning". Pursuit of this ideal [they continued] involves every phase in project delivery and in the life of the products that are components of the facility being constructed". Realisation of this lean ideal will bring construction closer to series production (i.e. manufacturing).

As pressure grows to fabricate ever more significant elements of buildings and other facilities offsite, it becomes increasingly important to create a smooth flow from raw materials arriving in the factory to the installation of the resulting sub-assemblies on-site. Predictable, JIT production in a 
factory is possibly easier than it is on-site, yet it is far from simple. Most factories serve a number of sites; some sub-assemblies will be unique and Engineered to Order (ETO) for a particular project and others, common to a range of projects and/or to a range of settings within a project, will be Made to Stock (MTS) (see e.g. Court 2009). Coordinating and synchronising flow in this environment requires meticulous real-time production planning.

\section{METHOD}

This paper considers two case studies and the author's experience in the context of a brief review of the literature on Critical Path Method, the Last Planner ${ }^{\circledR}$ System \& Just-in-time.

\section{PREFABRIACATION AND FLOW - A BRIEF LITERATURE REVIEW}

Prefabrication on its own is not enough to improve flow in construction production. Flow comes with end-to-end coordination \& synchronization of operations (see e.g. Modig \& Ahlstrom 2015). Work flows when everything (see Figure 1) comes together smoothly at the workface.

The predominant way the sector has attempted to create flow and predictability in construction operations over the last 50 years is to use approaches based on Critical Path Method (CPM). Endto-end coordination \& synchronization are critical, yet CPM and the software based on it (e.g. MS Project, Primavera) don't deliver either - over $60 \%$ of projects are delivered later than initially promised and often over-budget too (at the sector level see e.g. McKinsey 2017; at the project level see e.g. Howell \& Ballard 1995, 1998 and the many other authors who have confirmed that on conventionally managed sites only 50-60\% of the work planned each week gets done).

Although CPM-based approaches are used to manage production, they are not fit for purpose. There is no systematic check within CPM systems that work can be done (Ballard \& Howell 1995; 2003). Winch, (2002) suggested that project programs are often effectively formed during the tender or preconstruction period [by office planners] and quickly become enshrined within the master construction program and then constrain programmes developed later. In addition, it is impossible to maintain a complete, up-to-date plan in the way envisaged by the proponents of CPM-based project management (Koskela and Howell 2002).

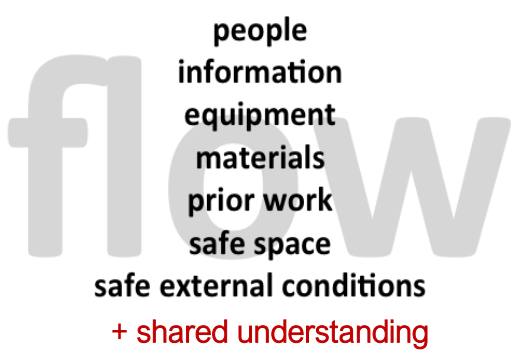

Figure 1. the eight flows required for work to be successfully done.

Sources: Koskela 2000; Pasquire \& Court 2013; graphic Mossman.

A CPM-based approach is neither a production management nor a production control system. There are eight flows that need to come together at the workface for successful construction assembly work (Figure 1). Shared understanding of the conditions of satisfaction (Flores 2012) is vital if suppliers are to create the value requested by their customers without the need for rework. 
The CPM process and associated software considers only one of these, prior work. If any of the other items is missing, the work cannot be started or cannot be finished. Even though it is the most common approach to project control, CPM is not able to control production because, as Kelly \& Walker noted as long ago as 1959 "The basic assumption that underlies [CPM] ... is that adequate resources are available to implement any computed schedule. CPM is blind to what can be done. CPM leads to unpredictable workflow and as Ballard \& Howell (1998) state "when it is impossible to determine what and how much work will be available at a future time, it is impossible to arrange for the specific resources needed, and it is impractical to develop detailed methods and to make detailed preparations for doing what could be widely different types of work. Thus the certainty of workflow from one production unit to the next is a key to productivity." One way to create more predictable, more certain, construction workflows is to use the Last Planner ${ }^{\circledR}$ System (LPS).

\section{Last Planner System - LPS}

Developed in the early 1990s by Ballard \& Howell (see e.g. 1994, 1995), LPS is a short-term planning system that aims to create more predictable production in construction and other projectbased production environments. It has proved itself on projects large and small over the last 25 years. LPS considers all of the flows presented in Figure 1 above (see Mossman 2015). LPS has successfully helped many projects using prefabricated elements. Skanska in Scandinavia chose to adopt LPS to help make their projects a reliable customer for just-in-time deliveries. When LPS is coupled with Building Information Modelling (BIM), it is possible to simulate the construction process to check the feasibility of installing large components and the flow of work.

CPM and LPS are very different ways of thinking about production. CPM pushes work into production based on a schedule prepared months or even years in advance; LPS pulls work into production when the next-trade-in-line believes it will it will have everything it needs to work on the preceding trades' completed work; LPS is based on what is happening in the present and on an informed view of what will happen in the immediate future while CPM looks back to the plan prepared months ago.

\section{Long lead items within LPS}

Any prefabricated items with long lead times (such as plant rooms, elevators \& escalators) require special attention within LPS. This does require attention to get it right and is not difficult to do. Any item with a lead time longer than the "look-ahead window" in which work is made ready (a feature of LPS), must be included in the milestone and phase schedules (two other features of LPS).

\section{Just-in-time (JIT)}

In construction JIT helps create predictability and flow in the context of LPS managed production. Taichi Ohno is credited with pioneering JIT at Toyota. Hopp \& Spearman (2000) describe how, by the 1970s and 1980s, the Japanese had developed a new style of manufacturing and associated techniques that became collectively known as Just-in-time (now lean). The way Ohno made this work effectively in the 1950s was by using a simple signalling system (kanban). This connected each step in the JIT process and synchronised them. Simultaneously it reduced the demand for management work - workers "pulled" the materials and sub-assemblies they needed from coworkers earlier in the process without the need for managers to intervene. JIT helps reduce waste by supplying parts only when the assembly process requests them with a kanban signal. 
Ohno was working in a series production, or manufacturing, environment (Toyota). As Vriehoef \& Koskela (2005) make clear, construction is generally different from series production. Ballard \& Howell (1995) is one of the earliest studies of the relevance of JIT to construction.

In construction kanban requests can go from anyone on-site to whomever is supplying what is required. The aim, in a construction workflow, is for the right parts (ETO \& MTS) to reach the assembly point with all the other 'flows' (in Figure 1) at the time they are needed and only in the quantity needed. If this flow process is to work, it needs to extend all the way back to the supplier of raw materials.

\section{CASE STUDIES}

The first case illustrates the importance of understanding the different capabilities of each supplier and of trust in the supply chain.

Hathaway Roofing switched to JIT lean production (Figure 2) almost 20 years ago so that it could better serve sites. The redesigned factory simplified the production paths for each of their main product types. In the redesigned factory, products flow. Most materials are delivered to the start of the production process on a JIT basis and never go into stores. At the end of the production process items are shipped to site.


Figure 2. the Hathaway Roofing factory before switching to lean JIT production (left) and after (right). Source: Swain \& Mossman (2003)

London Heathrow Terminal 5 client and main contractor, BAA, sought to minimize the risk of delays at site. They chose Hathaway Roofing to fabricate the 1500 roof panels in the north of England, about 6 hours by truck from the site. The transformed Hathaway factory was able to produce in one workday the panels that would be installed during the next workday and ship them to site overnight. They could produce them in the right order for installation. In this case, BAA decided that it wanted all 1500 panels in a warehouse close to site before any work started on the roof. What did they pay for that security of supply? ... for that huge buffer? 


\section{End-to-end coordination \& synchronization are critical}

The second case illustrates why it is important to consider the site as the customer for both JIT fabrication and JIT delivery of the right components in the right sequence at the right time - the whole system needs to be joined-up.

On a remote hydro-electric project in Northern Ontario the subcontractor responsible for supplying and installing the turbine and the generator used lean principles at site and lean manufacturing at its production facility, yet there was nothing lean about the way the equipment to be installed was shipped to site. The lean team in the factory produced what was needed at site in a way that optimized their local production system - they saw no reason to consider the needs of their colleagues at site. Materials were shipped in production order - not in installation order. The major items, the ETO parts, were checked prior to shipping but no-one thought to check the MTS items such as critical high-strength bolts of specific lengths. The lack of sufficient bolts to complete the installation added costs and considerable delays as the parts made their way from Europe through customs and along ice bound roads.

\section{DISCUSSION: JUST-IN-TIME PRODUCTION X2}

Why does the title speak of 'just-in-time production $x 2$ '? Because just-in-time production on-site is just as important as just-in-time production in the factories and fabrication shops that supply the site. Both the site and the fabrication shops rely on just-in-time deliveries. Together, these help on-time (or better) delivery of the project.

In Figure 3, a simplified example, the site is supplied directly by some suppliers and by two different fabricators producing ETO and MTS items. For work at site to flow smoothly and without interruption, the site needs just-in-time delivery from each of the fabricators and the other suppliers. Late delivery to site is clearly a problem - workers have to wait for work.

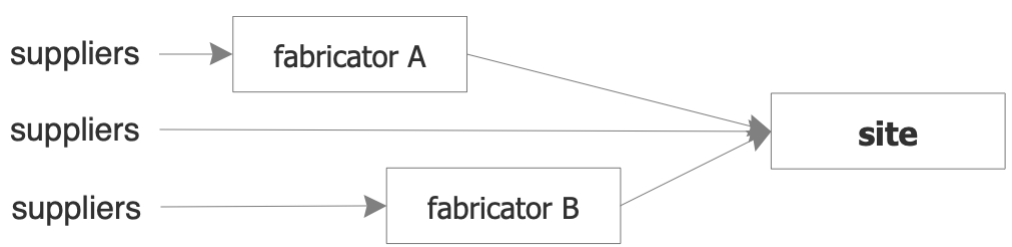

Figure 3. A simplified construction process.

It is not just the site that needs JIT delivery. Each of the fabricators needs JIT delivery too. So, in this simple system, kanban signals from site start a production process at each of the fabricators who in turn send kanban signals to each of their suppliers including the haulage company (or internal transport department) that will deliver the sub-assemblies to site. This process will only flow if JIT thinking is embedded in the end-to-end process.

There are at least two potential sorts of waste in the flow illustrated in Figure 3:

At the factory gate:

- sub-assemblies waiting to be delivered

- delivery trucks waiting to take sub-assemblies to site
At site:

- sub-assemblies waiting to be installed

- workers waiting for sub-assemblies to arrive 
Each of these add to the time it takes to complete the project and, generally, add to the price paid by the client/owner. Clients, owners and CM/GCs want the benefits of prefabrication and associated JIT supply, yet, as a consequence of traditional procurement strategies, are not generally willing (or are unable) to demand JIT production \& supply from their supply chain.

\section{DISCUSSION}

When a site is kept waiting for ETO sub-assemblies or critical MTS items that is a loss for the those waiting to install the sub-assembly on-site, as well as a delay for the client/owner and $\mathrm{CM} / \mathrm{GC}$. If the site is not ready to install a sub-assembly when it arrives there may be an additional cost (e.g. demurrage) to the haulier, the fabricator and/or the sub-contractor (often passed on to the client) or, if there is laydown space, the sub-assembly may be stored on site where it may:

- impede other activities and require moving one or more times

- be damaged by weather, site conditions machines or equipment - or by pilfering.

As we saw in the Terminal 5 roofing example, early delivery can add cost for off-site storage even if the product is not stored on site. The client/owner will ultimately pay these costs.

Avoiding or reducing all these additional costs requires:

- predictable production of sub-assemblies at a number of off-site fabrication shops owned by a number of independent fabricators serving a range of unique sites.

- predictable production at site

- predictable logistics connecting the site and the various fabrication shops.

There many uncertainties associated with each of these and LPS \& JIT can help to reduce them. LPS was developed in the context of Design-Bid-Build (DBB) contracting and CM/GCs do not need client approval to adopt LPS; they will need a collaborative culture within their supply team.

\section{Where JIT is not working}

While waiting for supply chain partners to adopt JIT principles it is possible for clients and constructors to foster JIT production on site by creating a buffer between the suppliers, fabricators and the site. A consolidation centre a short distance from the site is one way to do this. This was done for Terminal 5 (dti 2004) and for a number of buildings in the centre of London (TfL 2007) for example. Ideally materials are delivered to a consolidation centre no more than 7 days prior to their being required on site. The consolidation centre checks the materials delivered and returns any that are defective. Unnecessary packing can be removed before materials are delivered to site (reducing reverse logistics) and sometimes it is possible to minimise packaging at the fabrication shop as the sub-assembly will be weather protected from factory to site. Kanban signals from site trigger the delivery of materials and sub-assemblies JIT so that they can be moved directly to the part of the structure where they will be installed. A consolidation centre can provide a kitting service - separate but related items, say for a single space or zone, grouped and delivered together.

\section{Reducing vehicle movements}

In a 2017 article in the Dutch construction magazine Cobouw, van Amstel \& Postulart report that more than $15 \%$ of construction costs have to do with transport to and from construction sites and "30\% of the commercial traffic in Dutch cities is for construction sites - more than 200,000 delivery vans and 20,000 trucks on a daily basis". Building on the experience of the Hammerby Sjostad Logistics Centre, Stockholm, Sweden and Transport for London in the UK, Dutch construction 
companies and a transport company participated in pilot projects in Amsterdam and Utrecht. The projects were studied by the Netherlands Organisation for Applied Scientific Research (TNO) and Dutch universities. As in the London research a decade earlier, the results are significant:

- nearly $70 \%$ fewer transport movements to construction sites (reducing vehicle movements improves road safety as well as reducing pollution (Davies \& White 2015)),

- nearly $70 \%$ fewer CO2 (\& particulate) emissions, and

- up to $40 \%$ higher productivity at the site

- 3-5\% lower construction costs

- fewer complaints from people in the surrounding area. (van Amstel \& Postulart 2017)

The cost reduction alone is equivalent to doubling the profits of some constructors. That alone may be a reason for using a local consolidation centre even if JITx 2 is fully operational on a project. As project supply and delivery teams become more proficient at JIT, the space they will require at a consolidation centre will fall. This will allow smaller consolidation centres or existing centres to serve more projects in its locality.

\section{CONCLUSION}

Creating a smooth, predictable flow in construction production with off-site fabrication requires just-in-time delivery throughout the end-to-end construction supply chain. In practice this level of coordination \& synchronization of operations is not possible with traditional Critical Path Method. Over the last 25 years, the Last Planner System has shown itself capable of improving the predictability of site operations to a level where mixing site and off-site production is a realistic and cost-effective option.

Creating a buffer, such as a consolidation centre, between suppliers, fabricators and the site is one way to help the whole supply team learn to create predictable flow. There may even be arguments for doing this anyway as it reduces some of the undesirable externalities associated with construction. As JIT proficiency improves consolidation centres are able to serve more sites.

\section{Implications of failing to create flow in construction with high levels of pre-fabrication}

In the context of off-site fabrication, this paper shows that failing to fully implement just-in-time across an entire production system can reduce both productivity and profitability. This has the potential to disappoint clients/owners and slow take-up by:

- creating poor experiences of using off-site fabrication

- reducing or eliminating expected cost savings

- extending anticipated construction times.

\section{Ideas for further research}

- Designers tend to design for what they think any constructor can build. Not all constructors can or want to use prefabrication and off-site options, so in DBB procurement, use of prefabrication often requires significant design rework. Other than Integrated Project Delivery or Alliancing, are there ways to reduce that design rework?

- What are the typical costs of failing to synchronise production on- and off-site in terms of e.g.: time lost, financial loss, damage to sub-assemblies that arrive before the site is ready to install them, sub-contractor losses resulting from workers waiting for work, etc.

- Does JIT \& Pre-fabrication increase the sustainability of a construction project? 
- What is the best way to introduce the Last Planner System to a project?

- What is the best way to embed JIT thinking and processes in the end-to-end supply team?

\section{REFERENCES}

Ballard, Glenn. 1994. The Last Planner. Paper to the Northern California Construction Institute, Monterey, CA April 22-24

Ballard, Glenn \& Greg Howell. 1994. Implementing lean construction: Stabilizing workflow. in Alarcon, Luis (ed). 1997. Lean Construction 101-110.

Ballard, Glenn \& Greg Howell. 1995. Toward Construction JIT. in Alarcon, Luis (ed) (1997) Lean Construction 291-300

Ballard, Glenn \& Greg Howell. 1998. Shielding Production: Essential Step in Production Control. J. Constr. Engrg. and Mgmt., 124 (1) 11 - 17.

Ballard Howell (2003) Competing construction management paradigms. Proceedings of the Construction Research Conference, American Society of Civil Engineers, Honolulu, HI

Court, Peter. 2009. Transforming Traditional M\&E Construction into a Modern Process of Assembly EngD Thesis, Loughborough University

Davies, Glen \& Hannah White. 2015 Reducing accidents between construction vehicles and cyclists. Civil Engineering 168(3) 131-137 Institution of Civil Engineers.

dti 2004. Construction Logistics Consolidation Centres: An examination of new supply chain techniques. Dep't of Trade \& Industry, London

Flores, Fernando 2012 Conversations for Action and Collected Essays: Instilling a culture of Commitment in Working Relationships. CreateSpace

Hopp, WJ, \& ML Spearman. 2000. Factory Physics: Foundations of Manufacturing management; McGraw-Hill; New York

Howell, Greg \& Glenn Ballard. 1995. Factors affecting project success in the piping function. 2nd Ann Conf of IGLC, Albuquerque, NM in Alarcon ed 1997 Lean Construction 161-85

Kelley, James \& Morgan Walker. 1959. Critical-Path Planning and Scheduling. Proceedings of the Eastern Joint Computer Conference

Koskela, Lauri. 2000. An Exploration towards a Production Theory and its Application to Construction PhD Thesis, VTT, Finland

Koskela, Lauri \& Greg Howell. 2002. The underlying theory of project management is obsolete. Paper presented at PMI ${ }^{\circledR}$ Research Conference 2002: Frontiers of Project Management Research and Applications, Seattle, Washington. Project Management Institute

McKinsey Global Institute. 2017. Reinventing-Construction: a route to higher productivity.

Modig, Nicholas \& Per Ahlstrom. 2015. This is lean: resolving the efficiency paradox. Lean Construction Institute, Arlington, VA.

Mossman, Alan. 2015. Last Planner: $5+1$ crucial \& collaborative conversations for predictable design \& construction delivery. 40pp. http://www.villego.com/wpcontent/uploads/2017/02/Mossman-2015-Last-Planner.pdf 17Mar19

Pasquire, Christine \& Peter Court. 2013. An exploration of knowledge and understanding the eighth flow. IGLC

Swain, Brian \& Alan Mossman. 2003. "Smooth \& Lean” Quality World 29(3) 27-30

TfL 2007. Construction Consolidation Centres: An Assessment of the Potential for London wide use. Transport for London.

van Amstel, Walter P \& René Postulart. 2017. 'Slimme bouwlogistiek houdt steden leefbaar: chaos is een keuze' [Smart construction logistics keeps cities liveable: Chaos is a choice] Cobouw 
Vrijhoef, Ruben \& Lauri Koskela. 2005. Revisiting the three peculiarities of production in construction. Proceedings IGLC-13, July, Sydney, Australia 